\title{
On Work Stress of Knowledge Employees in Fashion Industry Meixiang $\mathrm{Hu}$ Jiangxi Institute of Fashion Technology, Nanchang, 330201, Jiangxi, China 1773461629@qq.com
}

\author{
Keywords: Fashion industry; Work stress; Knowledge employees; Strategy
}

\begin{abstract}
Nowadays, the garment industries are developing from the traditional manufacture industry to the culture creative industry in China. The knowledge employees in garment industry are facing some new challenges and work stress from high requirements for organizational management which are needed at the current circumstance. The article indicated that the work stress of knowledge employees in garment industry has reached a middle-up level. The researched discovered different characteristics of work stress on the basis of demographic variables through empirical research. In order to adhere to the philosophy of people-oriented, the organization should strengthen work stress management, which has high value and importance not only for improving the human resource management but also for enhancing the potentiality of knowledge employees and expanding organization performance practically at the same time in the future.
\end{abstract}

\section{Introduction}

Stress at work and in the family is a very common occurrence in our society that generates many health-related problems. During recent years, numerous studies have sought to define the term stress, raising many contradictions that various authors have attempted to establish some criteria, in subjective and not very quantitative ways, to try to reduce and even to eliminate stress and their effects at work and in the family context [1]. Under the background of the globalization, the information and the knowledge economy, people's former values, achievements and happiness are suffering from great impact. At present, our country is in an important stage of economic transition. With the process of nation policy and system reform, the structures of profit gainers are changing and the competition is more fierce than ever before, which all lead to the heave work stress for the groups of all wakes of life[2]. Generally speaking, more or heave work stress will have great effects to the spirit and body health of the staff and the organization. Recent years, creative nation construction has been put on the agenda. Especially the policy to develop the culture creative industry, which has put forwards new requirements to the production operation and management level. The garment needs more and more knowledge employees. These knowledge employees should master or possess the knowledge: market analysis of garment; style design; the supply of fabrics and accessories; model design; sample manufacture; typographic design; cutting; craft design; documentary; production management; marketing plan; production offer; storefront display and market management. As you know, those people are in sore need. However, there are a great contradiction between the supply and the acceptance. According to the survey of China Fashion Web, fashion designers and fashion pattern makers are in short of supply in garment enterprises. 150,000 fashion designers are in short in the garment enterprises, containing chief designers, design director, designers and assistant designers [3]. In a word, the shortage of talents has become the greatest resistance to achieve the great progress in the garment industry. The cultivation of owning knowledge and creative talents had become more and more important. The research to the work stress of knowledge employees in garment industry manifests the operation ideology of people-oriented, which has an important significance for attracting the talents and sustaining the talents. 


\section{Research Method}

Selection of the Sample. A knowledge employee means the people who master and apply the sign and the concept; knowledge and information. They bring creation and knowledge capital increment for the enterprises and put the actives as their vocation through the wisdom labor of creation, analysis, judgment, comprehension and designing. In fashion industry, knowledge employees contain fashion design, production, sales, administrative management and technology people [4]. In concrete terms, containing the staff as follows:1. Garment production technical, they are advanced technology workers of mechanical engineering, fabrics and accessory quality control assistant, tracker and craftsman; two. Garment research and design personnel, containing fabric and accessory development personnel, designers, model masters, sample machinists and the operators of controlling CAD; three. Garment sale and market personnel, containing purchasing personnel, market sales, store expansion and advertisement personnel; four. Other management personnel in garment enterprises, containing human resource and administrative management personnel.

I made some surveys to the samples which abide by the conditions. The questionnaire was sent in Nov. 2015. Accepting the questionnaires are these enterprises: Nanchang Yuxiu Taide Limited Company, Li-ning Sporting Goods Limited Company, Zhejiang Wenzhou Baoxiniao Group and so on, summing up more than 10 garment enterprises. 700 pieces questionnaire were distributed and 580 pieces questionnaire were recycled. The recycle ration is $71.4 \%$. After deleting the invalid questionnaire, the valid questionnaire is 520 pieces, and the valid ration is $89.7 \%$. The descriptions to the samples are as follows Table 1.

Table 1 The description to the research samples

\begin{tabular}{|c|c|c|c|}
\hline Project & Type & Number of People & $\%$ ( Percent) \\
\hline \multirow{6}{*}{ Age (years) } & $<30$ & 514 & 41.2 \\
\hline & $31 \sim 35$ & 115 & 22.1 \\
\hline & $36 \sim 40$ & 92 & 17.7 \\
\hline & $41 \sim 45$ & 53 & 10.2 \\
\hline & $46 \sim 50$ & 36 & 6.9 \\
\hline & $>50$ & 10 & 1.9 \\
\hline \multirow{2}{*}{$\operatorname{sex}$} & male & 222 & 42.7 \\
\hline & female & 298 & 57.3 \\
\hline \multirow{4}{*}{ Education Background } & Under junior college students & 68 & 13.1 \\
\hline & Junior college students & 146 & 28.1 \\
\hline & Senior college students & 261 & 50.2 \\
\hline & Master or above master students & 45 & 8.7 \\
\hline \multirow{5}{*}{ Working years (years) } & $<5$ & 163 & 31.3 \\
\hline & $5 \sim 10$ & 148 & 28.5 \\
\hline & $11 \sim 15$ & 102 & 19.6 \\
\hline & $16 \sim 20$ & 53 & 10.2 \\
\hline & $>20$ & 54 & 10.4 \\
\hline \multirow{4}{*}{ Month Income (yuan) } & $<3000$ & 202 & 38.8 \\
\hline & $3001 \sim 6000$ & 215 & 41.3 \\
\hline & $6001 \sim 9000$ & 70 & 13.5 \\
\hline & $>9000$ & 33 & 6.3 \\
\hline \multirow{5}{*}{ Marital Status } & unmarried & 173 & 33.3 \\
\hline & married & 315 & 60.6 \\
\hline & divorced & 28 & 5.4 \\
\hline & separated & 4 & 0.8 \\
\hline & widowed & 0 & 0 \\
\hline
\end{tabular}




\begin{tabular}{|l|c|c|c|}
\hline \multirow{3}{*}{ Working Field } & Production, operation & 143 & 27.5 \\
\cline { 2 - 4 } & Research and development, design & 112 & 21.5 \\
\cline { 2 - 4 } & Sales, market & 163 & 31.3 \\
\cline { 2 - 4 } & Personnel, administrative & 102 & 19.6 \\
\hline
\end{tabular}

The Extension of Table 1

\begin{tabular}{|c|c|c|c|}
\hline Project & Type & Number of People & $\%$ ( Percent) \\
\hline \multirow{3}{*}{$\begin{array}{c}\text { Belongings of the } \\
\text { organization }\end{array}$} & Stated-owned enterprises & 68 & 13.1 \\
\cline { 2 - 4 } & Private enterprises & 203 & 39.0 \\
\cline { 2 - 4 } & Overseas-funded enterprises & 124 & 23.8 \\
\cline { 2 - 4 } & Joint venture enterprises & 115 & 22.1 \\
\cline { 2 - 4 } & others & 10 & 1.9 \\
\hline
\end{tabular}

The Choice of Research Instrument. The theory behind the Job Content Questionnaire (JCQ) presumes that the "objective" social environment is measurable via self-report inventories such as the JCQ. Hence, it is expected that workers in identical work will respond highly similar [5]. The operation definition to the work stress is as follows: under the work environment, considering the interaction between the individual and the environment, the factors which bring impending and threat towards the work act on the individual and make the individual feel the reflection process of physiology, psychology and behavior [6].

Positive job characteristics, especially professional expertise and work variety, contributed to the explanation of "job satisfaction". The major contributors to "tension" and "emotional exhaustion" were negative characteristics, such as work pressure. The major contributors to "tension" and "emotional exhaustion" were negative characteristics, such as work pressure Work stress scale was determined on the base of former dialogue results, taking examples of OSL which was made by Cooper Sloan and Williams in 1988. The scale is composed by 23 questions in

The official survey, containing 6 dimension which are the work itself factors, role stress, personnel relationship, vocational development, organization system, organization style and the conflict between the job and the family.

Statistical Method. Collecting the data through the questionnaire and making statistical method to analyze the data information. The analysis of variance was used to analyze the variable, and the statistical soft Excel 2007 and SPSS 17.0 were also used in the analysis. Positive job characteristics, especially professional expertise and work variety, contributed to the explanation of "job satisfaction". The major contributors to "tension" and "emotional exhaustion" were negative characteristics, such as work pressure Positive job characteristics, especially professional expertise and work variety, contributed to the explanation of "job satisfaction". The major contributors to "tension" and "emotional exhaustion" were negative characteristics, such as work pressure

\section{Research Results and Analysis}

The Whole Situation of Work Stress. The whole average of work stress for the knowledge employees in garment industry is 60.67 , the standard deviation is 12,56 . The full mark of the questionnaire is 115 . The top mark is 99 , and the bottom is 24 , the average is above the middle value 57.5, which shows that the work stress of the staff is in the middle-up level. Due to the different projects in the dimension, the research arranges according to the average of the work stress dimension, from the top to the bottom are: the work itself factors $(64.2 \%)$, vocational development $(61.6 \%)$, organization system and style (56>3\%), role stress $(47.2 \%)$, the conflict of job and family (46.1\%), personnel relationship (45.9\%), which shows that the work stress comes from the work itself most. The work stress and the average value and standard deviation are showed in Table 2. 
Table 2 Work stress and the whole description of 6 dimension

\begin{tabular}{|c|c|c|c|c|c|}
\hline Dimension & Sample & Minimum & Maximum & Average & Deviation \\
\hline Work stress & 520 & 24.00 & 99.00 & 60.67 & 12.56 \\
\hline Work itself factors & 520 & 3.00 & 15.00 & 9.64 & 2.61 \\
\hline Role stress & 520 & 6.00 & 48.00 & 14.17 & 4.65 \\
\hline Personnel relationship & 520 & 4.00 & 18.00 & 9.18 & 3.13 \\
\hline Vocational development & 520 & 2.00 & 10.00 & 6.17 & 2.04 \\
\hline Organization style and system & 520 & 6.00 & 30.00 & 16.90 & 5.21 \\
\hline The conflict of job and family & 520 & 2.00 & 10.00 & 4.61 & 1.81 \\
\hline
\end{tabular}

\section{Summary}

After the empirical study, discovering that the work stress of knowledge employees in garment industry are at a middle-up level, and work stress has difference in the variable of demography. Positive job characteristics, especially professional expertise and work variety, contributed to the explanation of "job satisfaction". The major contributors to "tension" and "emotional exhaustion" were negative characteristics, such as work pressure [7]. According to the research results, in order to promote the development of garment industry, 3 suggestions and strategy are put forward as follows: Firstly, put the goal as the guiding, ensure the job responsibility and regulate the job roles. Through the empirical research, I discovered that the work stresses of knowledge employees are from themselves [8]. Therefore, in order to solve the problem of the work stress, it is necessary to carry out the stress management.

Secondly, take the principle of people-oriented and make the equal and effective incentive mechanism. The work stress has close relationship with the operation mechanism and style of the organization. Therefore, the equal and effective incentive mechanism must be set up first. In the Human Resource Management of the enterprise, the evaluation to the staff must consider the position, experience, ability and the degree of working hard [9]. As we all know, high salary is a decent way to keep the talents. Besides, excellent environment and promotion chance are all the important factors.

Finally, care about the talents. Develop the psychology and the stress guidance. Some staff who worked for more than from 10 to 15 years may have the great conflict between the job and the family. These people sometimes could not concentrate and have a lot of stress from other fields. Under the circumstance, the project of Employee Assistance Programs was put forward, which aims to solve the problems not only the staff themselves but also the staff's families [10]. The project had played an important role in the growth of the enterprises, and we should make it more and more perfect.

\section{References}

[1] David Cárdenas Gonzalo: Influence of cushioning variables in the world of work and in the family on the probability of suffering stress [J], Safety and Health at Work, 2016.02.003.

[2] L. Shi: on the Research Situation and Direction of Work Stress [J]. Psychological Science, 2003, 26(3): p: 494-497. (in Chinese )

[3] X. G. Liu: Brand Fashion Design [M], Shanghai, Donghua University Press, 2009. (in Chinese )

[4] F. Zhou: Reforms of University Teaching Methods [J]. Higher Education of Social Science, 2013, Vol.4 (1), pp. 24-26. 
[5] Roger Persson, Åse Marie Hansen and Anne Helene Garde: Can the job content questionnaire be used to assess structural and organizational properties of the work environment? International Archives of Occupational and Environmental Health, 2012, Vol.85 (1), pp.45-55

[6] K. Y. Ma and C. M. Wang: the New Research Process of Organization Work Stress [J]. Psychological Journal. 2003, 26(5):864. (in Chinese )

[7] N. C. G. M. Donders, J. W. J. Gulden, J. W. Furer, B. Tax and E. W. Roscam Abbing: Work stress and health effects among university personnel[J]. International Archives of Occupational and Environmental Health, 2003, Vol.76 (8), pp. 605-613.

[8] Anders Haug, Mia Borch Münster: Design Variables and Constraints in Fashion Store Design Processes[j]. International Journal of Retail \& Distribution Management, 2015, Vol.43 (9), pp. 831-848.

[9] X. L. Ouyang: Fashion Process [M]. Higher Education Publication, 2000, pp. 264.

[10]Eundeok Kim, Kim K.P. Johnson: Forecasting the US fashion industry with industry professionals - part 1: Materials and design[J]. Journal of Fashion Marketing and Management, 2009, Vol. 13 (2). 